\title{
Celiac Diseases - Global Demographic Context and Slovakia
}

\author{
Kvetoslava Rimarova ${ }^{1,2, *}$ \\ ${ }^{1}$ Institute of Public Health, University of P. J. Safarik, Faculty of Medicine, Košice Slovakia \\ ${ }^{2}$ Association of Parents, Friends of children and Youth with Celiac Disease in Košice, Slovakia \\ towards earlier diagnosis of CD has been observed. \\ Unawareness of CD by physicians probably still underlies \\ misdiagnosis and diagnostic delay $[11,12,13]$.
}

\section{Introduction}

Celiac disease (CD) affects people in all parts of the world. In last decades celiac disease thought to be a rare childhood syndrome, but currently is celiac disease known to be a common autoimmune genetic disorder [1]. More than 2 million people in the United States have the disease, or about 1 in 133 people [2]. Among people who have a first-degree relative (parent, sibling, or child) diagnosed with celiac disease, as many as 1 in 22 people may have the disease [2,3].

\subsection{Epidemiology - Global Population Trends of CD}

Until the 1970s the estimated global prevalence of CD in the general population was $0.03 \%$ [4]. The currently estimated prevalence is $1 \%$, with a statistical range of probability of $0.5-1.26 \%$ in the general population in Europe and the USA [5]. Occurrence rate of CD has been underestimated for many decades and the prevalence of this disease is increasing. Advances in diagnostic methods and improvement in screening have played a part in this observed prevalence increase, but environmental factors have also been important.

\subsection{Trends in Diagnosis and Screening of CD}

The introduction of gastro-intestinal endoscopic techniques in the 1970s opened new possibilities in CD detection and diagnosis. In addition development of genetic laboratory tests typically associated with CD (for examples HLA-DQ2 and HLA-DQ8), in the late 1980s and early 1990s, respectively, contributes to the disease identification. Developments of highly sensitive and specific serologic tests have also been important [6,7].

Some countries (f.e. Finland) implemented screening programs for detecting $\mathrm{CD}$ and this fact and results of the tests have contributed to a more realistic estimate of the actual disease prevalence [8]. The recognition that atypical, minor or extra-intestinal complaints can be associated with CD in patients of all ages and the detection of a range of histological abnormalities in the small intestine of patients with the disease have also contributed to improved diagnosis [9,10]. Despite the advances in screening for $\mathrm{CD}$, it remains under-diagnosed. In the general population, the ratio between patients with CD who received an accurate diagnosis and those who were never diagnosed as having the disease was reported to range from $1: 5.5$ up to $1: 10$. Since the 1980 s, a trend

\subsection{Demographic Distribution of CD}

Demographic distribution depends on genetic factors including the frequency of HLA alleles and environmental factors (infections, socioeconomic status, dietary habits). Those factors underlie the variations in the frequency of CD observed in different world regions. The HLA-DQ2 is more frequently found in white populations in Western Europe (20-30\%), Northern and Western Africa, the Middle East and Central Asia, whereas HLA-DQ8 is more prevalent in Latin America and Northern Europe [14,15,16].

Gluten products consumption is common in Northern Africa, South America and the north parts of India where gluten consumption is more frequent. The population of Arab-Berber origin living in Algerian Sahara part has the highest prevalence of CD among all world populations [17]. This is the closed population with limited external ties where high levels of consanguinity, high frequencies of HLA-DQ2 and gluten being used for explanation these findings [17]. Japanese and Chinese population has very low, almost negligible frequency of HLA-DQ2 (16). The occurrence of CD may vary within individual countries, for instance in different parts of India. This variation is probably due to differences in diet and to associations of specific genetic clusters and particular regions. Middle Eastern countries (Iran, Turkey, Israel and Syria) seem to have similar frequency rates of CD to those of Western countries [18]. Czech republic which has most similar pattern of celiac disease to the Slovak republic is showing estimated prevalence $0.45 \%$ [19].

\subsection{Slovak Republic - Epidemiology of CD}

Slovak republic doesn't have national registry of chronic celiac disease and also there is no population screening blood tests for CD. In 2012 there have been attempt to receive summary reports from all gastroenterology outpatient department (paediatric and also adult) about number of registered patients with CD. Estimated amount of celiac patients in 2012 in Slovak republic was approximately 13.463 what means occurrence rate 1:404. From these data we can suppose that celiac disease is under-diagnosed in Slovak population [20].

\subsection{Healthcare for Patients with Celiac Diseases}


Celiac patients in Slovakia (diagnosed by ESPGHAN) criteria are registered as chronic patients and undergoing through medical check one in 6 months or one in 12 months, depends on the current health condition of the patients ad also on the recommendation of gastroenterologist.

\subsection{Gluten-free Products in Slovak Republic}

Slovak system of health care and medical insurance is partially covering registered gluten-free products only for patients with confirmed CD. Gluten-free products for pharmacy distribution have to be registered and approved as gluten-free by detailed laboratory examination. Those products can patients receive on the principles of medical prescriptions in pharmacy. Health insurance companies are covering gluten-free products approximately from $60 \%$ of the price (flour, pasta, raw material) to 5-30\% (ready baked bread, additional gluten free cookies) [21].

The gluten-free products without health insurance coverage is possible to buy in large supermarkets, local supermarkets, drugstores, special food shops etc.

\subsection{Celiac Disease Non-profit Organisations}

Patients non-profit (non-governmental) organisations work as a support for the people suffering from CD. They base and maintain web pages [22], spread information, organise local meetings, organise summer camps for children with specific dietary needs. In Slovak republic are a few local organisations working for people with CD, they support CD patients and people needed gluten-free diet. The largest one organization is in Bratislava and is also a part of AOECS - The Association of European Coeliac Societies [23].

\section{Conclusions}

Celiac disease (CD) is a chronic immune-mediated inflammation of the small intestine caused by a permanent state of intolerance to ingested gluten proteins affecting genetically susceptible individuals. Geographic distribution depends on many internal factors (genetic HLA antigens presence) and also external factors (wheat diet, gluten diet, infection, socio-demographic factors, breastfeeding). Many factors have contributed to the increased prevalence of $\mathrm{CD}$ which can be diagnosed at all ages, not only paediatric age. Growing insight into the clinical presentation of CD has resulted in novel diagnostic, prognostic and therapeutic methods and highlights the importance of considering the current diagnostic criteria of CD and its complications, as well as the evaluation and development of new treatment.

Slovakia as a country of European Union has very good system of support celiac patients through the system of partial covering the price of gluten-free products based on medical prescription in pharmacy. Also the role of nonprofit organisations dealing with celiac disease in Slovak republic creates important milestone in the help and protection of people with celiac disease.

\section{References}

[1] Losowsky MS. A history of coeliac disease. Dig Dis 2008; 26:112-120.
[2] Fasano A, Berti I, Gerarduzzi T, Not T, Colletti RB, Drago S, Elitsur Y, Green PH, Guandalini S, Hill ID, Pietzak M, Ventura A, Thorpe M, Kryszak D, Fornaroli F, Wasserman SS, Murray JA, Horvath K. Prevalence of celiac disease in at-risk and not-at-risk groups in the United States: a large multicenter study. Arch Intern Med 2003; 163:286-292.

[3] Jacobson DL, Gange SJ, Rose NR, Graham NM. Epidemiology and estimated population burden of selected autoimmune diseases in the United States. Clin Immunol Immunopathol 1997;84:223243.

[4] Lohi S, Mustalahti K, Kaukinen K, Laurila K, Collin P, Rissanen H, Lohi O, Bravi E, Gasparin M, Reunanen A, Maki M. Increasing prevalence of coeliac disease over time. Aliment Pharmacol Ther 2007;26:1217-1225.

[5] Dube C, Rostom A, Sy R, Cranney A, Saloojee N, Garritty C, Sampson M, Zhang L, Yazdi F, Mamaladze V, Pan I, Macneil J, Mack D, Patel D, Moher D. The prevalence of celiac disease in average-risk and at-risk Western European populations: a systematic review. Gastroenterology 2005; 128:S57-S67.

[6] Sollid LM, Markussen G, Ek J, Gjerde H, Vartdal F, Thorsby E. Evidence for a primary association of celiac disease to a particular HLA-DQ alpha/beta heterodimer. J Exp Med 1989; 169:345-350.

[7] Ludvigsson JF, Brandt L, Montgomery SM. Symptoms and signs in individuals with serology positive for celiac disease but normal mucosa. BMC Gastroenterol 2009; 9:57.

[8] Maki M, Mustalahti K, Kokkonen J, Kulmala P, Haapalahti M, Karttunen T, Ilonen J, Laurila K, Dahlbom I, Hansson T, Hopfl P, Knip M. Prevalence of Celiac disease among children in Finland. N Engl J Med 2003; 348:2517-2524.

[9] Kaukinen K, Maki M, Partanen J, Sievanen H, Collin P. Celiac disease without villous atrophy: revision of criteria called for. Dig Dis Sci 2001;46:879-887.

[10] Wahab PJ, Crusius JB, Meijer JW, Mulder CJ. Gluten challenge in borderline gluten-sensitive enteropathy. Am J Gastroenterol 2001;96:1464-1469.

[11] Catassi C, Ratsch IM, Fabiani E, Rossini M, Bordicchia F, Candela F, Coppa GV, Giorgi PL. Coeliac disease in the year 2000: exploring the iceberg. Lancet 1994; 343:200-203.

[12] Virta LJ, Kaukinen K, Collin P. Incidence and prevalence of diagnosed coeliac disease in Finland: results of effective case finding in adults. Scand J Gastroenterol 2009; 44:933-938.

[13] Rampertab SD, Pooran N, Brar P, Singh P, Green PH. Trends in the presentation of celiac disease. Am J Med 2006; 119:355-14.

[14] Romanos J, van Diemen CC, Nolte IM, Trynka G, Zhernakova A, Fu J, Bardella MT, Barisani D, McManus R, van Heel DA, Wijmenga C. Analysis of HLA and non-HLA alleles can identify individuals at high risk for celiac disease. Gastroenterology 2009; 137:834-40, 840.

[15] Wolters VM, Verbeek WH, Zhernakova A, Onland-Moret C, Schreurs MW, Monsuur AJ, Verduijn W, Wijmenga C, Mulder CJ. The MYO9B gene is a strong risk factor for developing refractory celiac disease. Clin Gastroenterol Hepatol 2007; 5:1399-405, 1405.

[16] Cummins AG, Roberts-Thomson IC. Prevalence of celiac disease in the Asia-Pacific region. J Gastroenterol Hepatol 2009; 24:13471351.

[17] Catassi C, Ratsch IM, Gandolfi L, Pratesi R, Fabiani E, El AR, Frijia M, Bearzi I, Vizzoni L. Why is coeliac disease endemic in the people of the Sahara? Lancet 1999;354:647-648.

[18] Malekzadeh R, Sachdev A, Fahid AA. Coeliac disease in developing countries: Middle East, India and North Africa. Best Pract Res Clin Gastroenterol 2005;19:351-358.

[19] Vancikova Z, Chlumecky V, Sokol D, Horakova D, Hamsikova E, Fucikova T, Janatkova I, Ulcova-Gallova Z, Stepan J, Limanova Z, Dvorak M, Kocna P, Sanchez D, Tuckova L, TlaskalovaHogenova $\mathrm{H}$. The serologic screening for celiac disease in the general population (blood donors) and in some high-risk groups of adults (patients with autoimmune diseases, osteoporosis and infertility) in the Czech republic. Folia Microbiol (Praha) 2002; 47:753-758.

[20] Pekarkova B. et al. Celiac disease in Slovak republic. Books of Abstracts, Gastroforum, 2012.

[21] www.health.gov.sk.

[22] www.celiakia.sk.

[23] www.aoecs.org. 